\title{
Indacaterol/Glycopyrronium in the Treatment of Severe Respiratory Failure: Marked Improvement of Respiratory Failure in a Few Weeks - A Case Report
}

\author{
Riccardo Pistelli Maria Rosaria Castriotti Loredana Panico \\ Catholic University of Rome, Rome, Italy
}

\section{Keywords}

Indacaterol/glycopyrronium - Chronic obstructive

pulmonary disease $\cdot$ Severe respiratory failure

\begin{abstract}
Chronic obstructive pulmonary disease is a highly prevalent disease, especially in the aging population, associated with several functional disabilities and a high economic burden. Dual bronchodilation with prefixed associations of long-acting $\beta_{2}$-agonists and long-acting muscarinic antagonist have a significant role in the management of this condition. The newer combination, indacaterol/glycopyrronium, is useful as a once-a-day therapy and has proven superior to other treatment strategies including inhaled corticosteroids for improving symptoms and clinical condition with a very rapid effect. We report our experience with a patient suffering from severe respiratory failure who improved significantly when the indacaterol/glycopyrronium combination was added to his therapy.

(c) 2018 S. Karger AG, Basel
\end{abstract}

\section{Introduction}

Chronic obstructive pulmonary disease (COPD) is a very common disease with high rates of morbidity and mortality worldwide and a prevalence increasing with age [1]. However, it is both preventable and treatable as it regards the progressive decline in lung function [2]. Pharmacological treatment can control symptoms and reduce the number and frequency of acute exacerbations requiring hospital admission $[3,4]$. The new Global Strategy for Diagnosis, Management and Prevention of COPD (GOLD 2017) guidelines suggest that prolonged bronchodilation with long-acting muscarinic antagonists (LAMA) and/or long-acting $\beta_{2}$-agonists (LABA), with or without inhaled corticosteroids (ICS), should be the strategy of choice in COPD patients $[2,3,5]$. Of note, ICS should be reserved only for symptomatic and frequently exacerbating COPD patients [5].

LABA and LAMA can be used alone or in prefixed combinations, the latter maximizing their bronchodilation through a synergic effect [6]. Newer agents, such as indacaterol and glycopyrronium, which have a prolonged duration of effects up to $24 \mathrm{~h}$, are the main molecules used in fixed combinations. The coadministration of these two

\section{KARGER}

(C) 2018 S. Karger AG, Basel

E-Mail karger@karger.com

www.karger.com/res
Riccardo Pistelli

Largo Francesco Vito, 1

IT-00168 Rome (Italy)

E-Mail riccardo.pistelli@unicatt.it 
bronchodilators leads to a synergistic improvement of bronchodilation, by leveraging different receptor types at submaximal doses with enhanced therapeutic benefits and reduced dose-dependent side effects [7, 8], and thus making these drugs stand out in the pharmacological armamentarium.

We present the case of a patient with severe respiratory failure whose lung function remained severely compromised with conventional therapy, but showed an immediate and marked improvement after introducing the indacaterol/glycopyrronium combination to his therapy.

\section{Case Description}

A 72-year-old man with a previous history of heavy smoking with chronic cough and mucus presented to the outpatient clinic for severe dyspnea with a modified Medical Research Council (mMRC) score of 3 . His shortness of breath had been progressively worsening over the last 2 years, following a car accident with multiple rib fractures, lung contusion, and hemothorax. On admission, chest radiography showed multiple areas of lung and pleural fibrosis coupled with a raised hemidiaphragm on the left side, whereas only a slight increase of lung transparency was noted on the right side. The respiratory rate was mildly increased, with the patient maintaining an upright thorax position while sitting and his lips showing evident cyanosis. Diffuse reduction of lung sounds was perceived on the left hemithorax, with some wheeze and crackles audible on the right side.

Spirometry revealed a reduction of total lung capacity to $72 \%$ of the predicted value, with a marked reduction of forced vital capacity (FVC, 65\%) and forced expiratory volume in the first second $\left(\mathrm{FEV}_{1}, 45 \%\right)$. The $\mathrm{FEV}_{1} / \mathrm{FVC}$ ratio was $55 \%$ (normal value $>70 \%$ ). The arterial blood gas analysis revealed a $\mathrm{PaO}_{2}$ pressure of $35 \mathrm{~mm}$ $\mathrm{Hg}$ and $\mathrm{PaCO}_{2}$ pressure of $52 \mathrm{~mm} \mathrm{Hg}$, with a $\mathrm{pH}$ of 7.41. Given the diagnosis of acute severe respiratory failure, immediate hospital admission was deemed necessary for the patient, but he refused hospitalization. The following therapy was then prescribed for 2 weeks: prednisone $50 \mathrm{mg}$ once daily, cefditoren/pivoxil $400 \mathrm{mg}$ twice per day, ipratropium bromide $80 \mathrm{mg}$ and salbutamol $400 \mu \mathrm{g}$ 4 times a day by aerosol, and low-flow oxygen through a Venturi mask with a $\mathrm{FiO}_{2}$ of 0.28; a follow-up visit was scheduled at the end of this treatment.

When the patient presented to the clinic for follow-up, arterial blood gases showed only little improvements $\left(\mathrm{PaO}_{2} 41 \mathrm{~mm} \mathrm{Hg}\right.$ and $\mathrm{PaCO}_{2}$ unchanged), but dyspnea and general discomfort were still present. Thus, the therapy was modified as follows: prednisone 25 mg once daily for 2 weeks and then $12.5 \mathrm{mg}$ once daily until the follow-up visit, oxygen as before, and the prefixed inhaled combination indacaterol/glycopyrronium once daily. A control visit was scheduled 4 weeks later.

At that time, the clinical situation of the patient was substantially improved: dyspnea decreased (mMRC score 2) and $\mathrm{PaCO}_{2}$ was normalized, whereas $\mathrm{PaO}_{2}$ had reached $51 \mathrm{~mm} \mathrm{Hg}$. Oral steroids were switched to ICS (fluticasone propionate $500 \mu \mathrm{g}$ twice per day), oxygen $\mathrm{FiO}_{2}$ was reduced to 0.24 , indacaterol/glycopyrronium was maintained. After 3 months, the patient is slowly pro- gressing $\left(\mathrm{PaO}_{2}\right.$ up to $\left.58 \mathrm{~mm} \mathrm{Hg}\right)$, and the clinical question of whether to interrupt ICS with the patient under strict supervision is burning.

\section{Discussion}

The progressive decline in lung function, typical for COPD, is responsible for high morbidity and mortality rates [2], with estimates of COPD as the fourth leading cause of death worldwide, going for third place. Of note, acute COPD exacerbations requiring hospitalization carry a 3 -fold higher mortality rate in the aging population [9], the subgroup of patients in whom COPD prevalence is the highest [1]. COPD accounts for about $6 \%$ of all deaths globally [10].

Importantly, COPD impairs the functional capacities of the individuals, and thus their working skills are also affected [11]. All these features imply that COPD carries a high economic burden [1].

The pharmacological strategies currently available for COPD patients mainly focus on prolonged bronchodilation, as suggested by the GOLD 2017 guidelines, as a way to improve symptoms and reduce exacerbations. LAMA and LABA, either alone or in combination, are the most important drugs in this field, together with ICS $[2,5]$. The fixed combinations show a synergic effect of maximized bronchodilation which allows for a lower rate of dosedependent side effects [6].

Moreover, the recent CRYSTAL study, focused on the combination of indacaterol and glycopyrronium, showed the superiority of the assessed combination over the association of LABA/ICS or LAMA in reducing symptoms and rapidly improving lung function [12-14]. Of note, the improvement of dyspnea is evident immediately after the switch from the previous treatments [13]. This evidence further supports the positive effects shown with indacaterol/glycopyrronium on exacerbation prevention versus salmeterol/fluticasone in the FLAME study.

This combination shows a synergistic action for improved bronchodilation [6], secondary to reciprocal potentiation of the two molecules [15]. Several possible mechanisms are advocated for this synergy: the high density of $\beta_{2}$-adrenergic receptors and the pathogenic role of neurogenic cholinergic mechanisms result in the leveraging of different receptor types at submaximal doses, increasing the therapeutic benefits and minimizing the dose-dependent side effects $[7,8]$. Laboratory studies have shown that $\beta_{2}$-adrenoceptor agonists activate prejunctional $\beta_{2}$-adrenoceptors to reduce acetylcholine re- 
lease, and that an inhibitory crosstalk may exist between M3 receptors and $\beta_{2}$-adrenoceptors in airway smooth muscle cells $[15,16]$.

All these speculations may explain the clinical improvement of our patient when the indacaterol/glycopyrronium combination was started. Notably, the patient markedly improved after just a few weeks of indacaterol/glycopyrronium, whereas the previous treatment did not prove efficacious in improving his clinical condition.

\section{Acknowledgement}

The authors thank Luca Giacomelli, $\mathrm{PhD}$, for providing medical writing on behalf of Content Ed Net; this assistance was funded by Novartis Farma SpA.

\section{Financial Disclosure and Conflicts of Interest}

The authors have no conflicts of interest directly relevant to this paper.

\section{References}

1 Wheaton AG, Cunningham TJ, Ford ES, Croft JB: Employment and activity limitations among adults with chronic obstructive pulmonary disease - United States, 2013. MMWR Morb Mortal Wkly Rep 2015;64: 289-295.

2 Global Initiative for Chronic Obstructive Lung Disease (GOLD 2017): Global Strategy for the Diagnosis, Management and Prevention of Chronic Obstructive Pulmonary Disease. Updated 2017. www.goldcopd.org.

3 Baty F: Comorbidities and burden of COPD: a population based case-control study. PLoS One 2013;8:e63285.

4 Wedzicha JA: Indacaterol-glycopyrronium versus salmeterol-fluticasone for COPD. N Engl J Med 2016;374:2222-2234.

5 Vogelmeier CF, Criner GJ, Martinez FJ, Anzueto A, Barnes PJ, Bourbeau J, Celli BR, Chen R, Decramer M, Fabbri LM, Frith P, Halpin DM, López Varela MV, Nishimura M, Roche N, Rodriguez-Roisin R, Sin DD, Singh D, Stockley R, Vestbo J, Wedzicha JA, Agustí A: Global Strategy for the Diagnosis, Management, and Prevention of Chronic Obstructive Lung Disease 2017 Report. GOLD executive summary. Am J Respir Crit Care Med 2017; 195:557-582.
6 Ficker JH: Role of dual bronchodilators in COPD: a review of the current evidence for indacaterol/glycopyrronium. Pulm Pharmacol Ther 2017;45:19-33.

7 O’Donnell DE, Casaburi R, Vincken W, Puente-Maestu L, Swales J, Lawrence D, Kramer B; INABLE 1 study group: Effect of indacaterol on exercise endurance and lung hyperinflation in COPD. Respir Med 2011; 105:1030-1036.

8 Rossi A, Centanni S, Cerveri I, Gulotta C, Foresi A, Cazzola M, Brusasco V: Acute effects of indacaterol on lung hyperinflation in moderate COPD: a comparison with tiotropium. Respir Med 2012;106:84-90.

9 Connolly MJ: Admissions to hospital with exacerbations of chronic obstructive pulmonary disease: Effect of age related factors and service organisation. Thorax 2006;61:843-848.

10 Vestbo J, Hurd SS, Agusti AG, et al: Global Strategy for the Diagnosis, Management, and Prevention of Chronic Obstructive Lung Disease: GOLD executive summary. Am J Respir Crit Care Med 2013;187:347-365.

11 Patel JG, Nagar SP, Dalal AA: Indirect costs in chronic obstructive pulmonary disease: a review of the economic burden on employers and individuals in the United States. Int J Chron Obstruct Pulmon Dis 2014;9:289-300.
12 Wedzicha JA, Banerii D, Chapman KR, Vestbo J, Roche N, Ayers RT, Thach C, Fogel R, Patalano F, Vogelmeier CF; FLAME Investigators: Indacaterol-glycopyrronium versus salmeterol-fluticasone for COPD. N Engl J Med 2016;374:2222-2234.

13 Vogelmeier CF, Gaga M, Aalamian-Mattheis M, Greulich T, Marin JM, Castellani W, Ninane V, Lane S, Nunez X, Patalano F, Clemens A, Kostikas K; CRYSTAL study investigators: Efficacy and safety of direct switch to indacaterol/glycopyrronium in patients with moderate COPD: the CRYSTAL open-label randomised trial. Respir Res 2017;18:140.

14 Mahler DA, Keininger DL, Mezzi K, Fogel R, Banerji D: Efficacy of indacaterol/glycopyrronium in patients with COPD who have increased dyspnea with daily activities. Chronic Obstr Pulm Dis 2016;3:758-768.

15 Cohen JS, Miles MC, Donohue JF, Ohar JA: Dual therapy strategies for COPD: the scientific rationale for LAMA + LABA. Int J Chron Obstruct Pulmon Dis 2016;11:785-797.

16 Mahler DA, Decramer M, D'Urzo A, et al Dual bronchodilation with QVA149 reduces patient-reported dyspnoea in COPD: the BLAZE study. Eur Respir J 2014;43:1599_ 1609.
Indacaterol/Glycopyrronium in the Treatment of Severe Respiratory Failure
Respiration 2018;95(suppl 1):19-21 DOI: $10.1159 / 000487181$ 